Filolo, y Lingüís. 4(2): 25-30, 1978

\title{
MARCIA Y CORNELIA EN EL POEMA DE LUCANO
}

\section{Francisco Vindas Chaves*}

El mayor poema histórico, La Farsalia, no puede pasar inadvertido por quien desea constatar en qué predicado estuvo el concepto de la femineidad por parte de los escritores más representativos del primer siglo del imperio romano.

La obra de Marco Anneo Lucano no retoma mujeres contemporáneas del autor; las dos figuras femeninas que campean con fuerte relieve en el poema, pertenecen a una época pasada: son lustre y decoro de la Roma republicana; pero la elaboración poética que de estas figuras históricas Lucano ha realizado -en las voces que él les da, en la luz en que pone los actos de sus vidas- se nos brinda el ideal femenino del cantor de Pompeyo, tal cual pudo concebirlo en la edad imperial.

¿Qué clase de almas poseen las dos heroínas del poema de Lucano?

Rígidamente estoica es el alma de Marcia: Cada uno de sus actos sigue fielmente el ritmo de vida que la doctrina le impone; su voluntad no es más que un silencioso asentimiento de la de su marido, obligándose al sacrificio y renuncia de todo cuanto ha sido gloria, comodidad, orgullo de la existencia.

Para comprender la figura de Marcia, para verla en su límpida luz, debemos olvidar nuestra actual psique moderna, liberarnos de los conceptos morales que nos son harto familiares, modelar nuestro pensamiento de acuerdo a los preceptos del estoicismo más rígido y a la sombra de éstos considerar la mujer de Catón y formular los juicios.

El criterio de la Stoa era muy diverso del cristiano y del moderno -y por lo tanto Catón, que es para nosotros el más ilustre y perfecto representante de aquella - en cuanto al matrimonio y a la mujer como tal. Esta es considerada solamente como el ser que la Naturaleza ha criado en calidad de coeficiente necesario para que el hombre perpetúe la especie.

* Profesor de la Universidad de Costa Rica.
Su más alto oficio es la maternidad: cuanto más numerosa prole dé al estado, tanto más benemérita será a los ojos de la patria; pero el hombre no debe sentir hacia ella ninguna clase de celo ni pretender su exclusiva posesión.

Diógenes Lercio en el libro VII, 131 de su

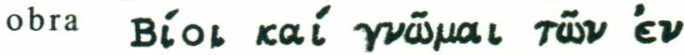

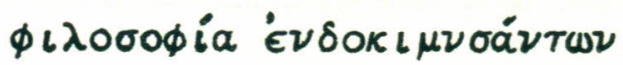

dice conı Zenón y Crisipo, cada uno

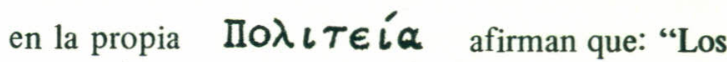
sabios deben tener en común las mujeres, sirviéndose cada uno de aquélla que le ocurra y, dejando a un lado cualquier sentimiento de celosía, que podría suscitarse si se considerase esta comunidad como un adulterio, converjan todo el amor en sus hijos, amándolos todos con afecto paterno." (1)

Si se considera, pues, a la luz de esta doctrina, el hecho de que Catón ceda Marcia a Quinto Hortensio para que pueda tener hijos y después a la muerte de éste, vuelva a esposarla, tal cosa nos parecerá perfectamente coherente con sus principios filosóficos, no obstante ser reprobable y por añadidura inconcebible en un alma honesta, desde el punto de vista de la moral común moderna que exige e impone la exclusividad en la posesión de la mujer.

El episodio de Marcia y Catón en el poema de Lucano (2) nos muestra la mujer que después de verificados los funerales del segundo marido, Quinto Hortensio, acude con la cabellera aún desgreñada, sucia por la ceniza fúnebre, con su vestido de luto, a la casa de Catón, para suplicarle le vuelva a tomar como su señora. Ahora, vieja, exhausta, deshecha, no aspira más que a morir como su esposa, a fin de que la lápida sepulcral la consagre para siempre como MARCIA CATONIS.

Si por obedecerle se separó del lado de Catón y pasó a otras nupcias, ahora que ha cumplido con su obligación y ha tornado libre por la muerte de Hortensio, suplica a Catón volverla a admitir en su 
antigua casa que la vio joven y feliz esposa, y espera ser acogida para condividir la afanosa vida de Catón, deseando tener la dicha de sufrir junto a él.

Hae flexere virum voces y Catón vuelve a tomarla como su esposa; y son nupcias calladas y silenciosas de personas que renuevan la antigua unión no para gozar la vida, sino para terminarla juntos, para encontrar paliativos a los trabajos y afanes de las tristes horas que han de pasar en el mutuo afecto consciente y tenaz.

El gran talento de Dante comprendió tan bien la sublimidad del acto de Catón que en ningún momento ensombrece por nada la claridad diamantina - de su nobilísima figura, y jamás somete a entredicho tal proceder.

En el Convivio (3) después, dando un sentido de exquisita alegoría, expone así este admirable episodio del poema de Lucano: "Aquel gran poeta Lucano, en el canto segundo de la Farsalia . . . dice que Marcia retornó a Catón y le pidió y suplicó que la debía de recibir ... ¿Y qué dice Marcia a Catón? Mientras en mí hubo vigor, en tanto que en mi existió la virtud maternal, yo hice y llevé a feliz cumplimiento todos los mandatos . . . Dice: Y tuve dos maridos ... Ahora, agrega Marcia, que mi vientre está laxo e incapaz de parir, a ti me acojo, no teniendo más encantos que ofrecer a algún otro esposo ... Y agrega Marcia: Concédeme los pactos de los antiguos lechos, dame tan sólo el nombre del maridaje. Permite que al menos yo en esta senta vida sea llamada tuya".

$\mathrm{Y}$ en el Purgatorio, de nuevo Dante, en el episodio del encuentro con Catón (c. 1, v. 30-108) celebra "los ojos castos" de Marcia, aquellos ojos testigos y reveladores de la virtud que la hizo infinitamente querida al corazón de Catón.

Pero si estoica es el alma de Marcia y como tal fue idealizada en el siglo $1^{\circ}$, no por eso es menos francamente humana, la figura de Cornelia, con humanidad tan elegida, que exalta su origen divino ni tampoco desprovista de aquella exquisita femineidad que armoniza en toda época con el ritmo de los sueños. Podemos comprenderla nosotros con rapidez extrema, ya que es el ideal femenino de ayer, es el de hoy y por sus profundas raíces humanas de su sentimiento, será también el de mañana.

Para personificarnos a Marcia, Lucano se inspiró austeramente en las ideas de su fe estoica; para retratar, a manera de una nueva creación, a la mujer de Pompeyo, Lucano se abandonó por entero al ardor de su ingenio, al ímpetu canoro de su arte poética, expresando aquel ideal de belleza moral que vivía ya de vida inmortal en la más fresca vena poética de su alma.

Plutarco, en la vida de Pompeyo, nos ha descrito una bella mujer, inteligente, provista de alma refinada por vasta cultura literaria y científica, adornada de virtuosidad musical, que junto al gusto por las ciencias exactas aunaba también al de las especulaciones filosóficas; era al mismo tiempo buena, recogida en una vida austera y pura y a la vez mujer devota y afectuosa.

Lucano por su parte, con intuición de gran poeta, con mano delicada y sabia, propia de piscólogo agudo, hizo que de aquella crisálida de bondad inteligente, de elevado y noble pensamiento se desarrollase, merced a la gloria de su arte, una mariposa extraordinariamente bella, una criatura de pasión.

Plutarco nos dice que el matrimonio de Pompeyo con Cornelia no tuvo el consentimiento de sus contemporáneos: algunos encontraban poco conveniente y juicioso que aquel gran hombre uniese su edad madura a una bella juventud aún fresca; otros, por su parte, juzgaban no muy bien elegido el momento para la dicha del nuevo himeneo.

Lucano, en cambio hace que aquel amor -que fue para ambos una ebriedad y ebriedad compartida - fuese para Pompeyo el oasis, el refugio, el consuelo de su agitada vida y para Cornelia la esencia de su vida y de su destino.

$\mathrm{Su}$ figura de esposa enamorada irrumpe llenando de luz el vacío dejado por la sombra de Julia en el corazón de Pompeyo. Cornelia enciende en Pompeyo una nueva llama de Pasión; liga altivamente su floreciente juventud con quien está en el declinar de su vida, con pleno consentimiento de sus labios y corazón; comparte ahora con él la amargura atroz de las desilusiones que el porvenir le tiene reservadas; se dispone a recibir impertérrita los golpes que la fortuna adversa asestará sobre el gran Pompeyo:

"haereat illa tuis per bella per aequora signis dum non securos liceat mihi rumpere somnos. Et nullum vestrum vacuum sit tempus amori, sed teneat Caesarque dies et Iulia noctes".

$$
\text { III, 24-27 }
$$

En el breve ámbito de estos versos, Lucano fija para siempre aquello que será el ritmo de la vida 
de Cornelia; desde este momento hasta el extremo tormento de la matanza de Pompeyo, hasta el deseo loco del fin que aporta paz a su espíritu quebrantado, la veremos seguir el destino de Pompeyo, avasallada por el peso de su corazón dolorido, transida de ansia y angustia, siempre más afanada y siempre más desesperada.

La vida de la mujer, por lo general, goza más de episodios interiores de su espíritu y de su psique que de los sucesos externos, y así la figura de Cornelia se traza y se colorea a la luz de la pasión que agita y reside en su alma: y ésta es su belleza y aroma, su candente y solemne poesía.

Los sucesos apremian amenazantes.

Pompeyo preocupado por las nuevas fuerzas que Julio César dispone en el campo y a manera de presagio de una derrota, piensa alejar de su lado a su compañera adorada para enviarla a lugar seguro, lejos de los peligros de una retirada precipitada; y a un mismo tiempo procura fortalecerse para la nueva prueba de armas con una vigilia de severa disciplina, ajena a momentos amorosos y blanduras enervantes de la vida. $\mathrm{Y}$ al primer despertar de Cornelia, con afectuosas pero resueltas palabras le comunica sus temores por la áspera empresa que se prepara y su deseo inquebrantable de que ella se vaya lejos, a un lugar seguro y disponga, tal vez, de un refugio.

El coloquio de los dos cónyugues antes de dejarse la víspera de un acontecimiento que podrá decidir de sus suertes en el porvenir, encierra tanta belleza que justifica la gloria del poeta Lucano; pocas páginas entre todas las literaturas, pueden remontarse a la perfección de este fragmento, dado su vivacidad dramática, el ímpetu lírico, la aguda finura psicológica, el sincero calor de sentimientos. $Y$ todos estos variados elementos se entrelazan en admirable armonía y triunfan en una expansión de majestuosa belleza.

Cornelia suplica por todos los medios a su alcance no ser alejada de su esposo en aquel momento de mayor peligro; le recuerda su fidelidad integra; el amor eterno que liga a ambos hacia un único destino; le reitera poseer fuerza de ánimo para saber resistir cualquier golpe de desventura; cualquier suerte, aún la más desventurada y triste será para ella alegre, con tal de compartirla con su Pompeyo; e intenta hasta de convencerlo para acogerse en la seguridad de un refugio, disuadiéndolo del combate.

A intervalos, la voz de Cornelia se reviste ya con los tonos de plegaria, ya con los del más fiero ímpetu de indignación y en sus palabras -ya dulces, ya violentas - se manifiesta toda la fiebre, todo el afán, todo el dolor que le afligen.

Más cuando Cornelia ve a su Pompeyo sordo a sus súplicas, decidido en sus propósitos, la rebelión del alma de Cornelia es más fuerte que el tormento y el amor: salta del lecho loca de dolor y desea con acto de supremo desdén alejarse de la tienda sin un gesto de afectuosa despedida que incluso podría ser el último" Demasiado se confía a sus débiles fuerzas de mujer; a la excitación improvisa sucede la postración y el abandono de toda energía física y cae privada del sentido apenas transpone el umbral de su estancia. Transportada sobre la nave que deberá conducirla lejos, a la isla de Lesbos, en Mitiline, Cornelia comienza su nueva vida de desconsolada soledad, de ansia pavorosa, de latidos indecibles. El deseo agudo por su marido, llega hasta el espasmo, agita su sueño, mete una fiebre ardiente en sus venas y una indefinida esperanza en el corazón. En las noches agitadas ella sueña tener a su lado a Pompeyo y deja intacta para él la orilla de la cama, demasiada amplia para ella y pide a los dioses le concedan la dicha de reunirse junto a él.

¡Pero su pobre amor arde solitario y bien triste desilusión le preparan los Númenes!

... sed non Superi tam laeta parabant:

instabat miserae Magnum quae redderet, hora.

$$
\mathrm{V}, 14-15
$$

Todo es paz en torno de Cornelia en aquella remota isla, pero incesantemente es el tumulto en su alma; una sola en su ocupación todos los días: escudriñar sin cansarse, con ávida mirada, hacia el ex tremo horizonte, sin que jamás aparezca una nave latina que le traiga noticias de Pompeyo y de sus hechos bélicos.

$\mathrm{Y}$ un día, finalmente, un barquillo aparece en lontananza ...

Farsalia-ha decidido la suerte de Roma, aportando completo triunfo para Julio César y la derrota para Pompeyo.

Es ahora Pompeyo, quien vencido y humillado se dirige adonde su esposa; viene a comunicarle el resultado del destino y a retomarla para que siempre conviva a su lado y vierta sobre su alma exacerbada el bálsamo de su afecto, igualmente devoto tanto en la prosperidad como en la adversidad.

Cornelia coıre hacia la orilla de la playa y antes de que Pompeyo hable, Cornelia lee la triste 
nueva y sin el menor grito se abalanza en los brazos abiertos de su esposo.

Lucano muestra una fineza maravillosa de intuición en el presentarnos en ese mundo mudarse de color de Cornelia, junto con el deliquio improviso, la plenitud de los sentimientos opuestos que agitan a la desventurada dama; aquella tácita manifestación de sufrimiento nos dice todas las impaciencias, los ardores, los ímpetus y las fiebres de la prolongada vigilia de espera, nos dice la conmoción violenta del momento de conseiente desdicha irreparable.

Es la revelación de todo esto, profundamente humano y maravillosamente heróico, que campea en el alma de la mujer de Pompeyo.

Una vez que Pompeyo se rehace, empieza a confortarla y con afectuosas y elevadas palabras la reanima; palabras estampadas en el precepto estoico que impone calma resignación en los dolorosos avatares de la vida. Ella, descendiente de la ilustre familia Escipiónica, fiel a la tradición de fortaleza de ánimo propia de su gloriosa prosapia, debe sacar, tomar el coraje para sobrellevar con dignidad la dura prueba que el Destino le ha deparado.

El ímpetu adverso de la fortuna que se cierne sobre Pompeyo, prepara la gloria de Cornelia dentro de las generaciones futuras: será el afecto inmenso, inmutable, que ahora hacia el marido vencido, abandonado, prófugo, se volverá aún más solícito, más fiel, más confortable.

$\mathrm{Y}$ en verdad bastan estas simples palabras de Pompeyo para la gloria inmortal de Cornelia:

"et tua cum fatis pietas decertet et ipsum quod sum victus ama; nunc sum tibi gloria maior, a me quod fasces et quod pia turba senatus tantaque discessit regum manus".

$$
\text { VIII, 77-80. }
$$

Si en las anteriores palabras incuba una nostalgia sin límite de revivir en el círculo de la inagotable piedad y amor fiel, también existe la afirmación alta, solemne que lo consagra para siempre como modelo de la fidelidad en la ilimitada devoción de la compañera preferida y bien amada.

Ya no la falta de honores, ni la evaporación de todo augusto sueño de predominio, ni la triste soledad, ni la incertidumbre de una fuga sin escolta ni provisiones podrán apartar de su corazón a la admirable Cornelia, quien se halla dispuesta a com- partir junto con Pompeyo las amarguras de la nueva vida errante y de persecusión. Antes bien, resultará su débil persona un escudo para su hombre y querrá darle con su alivio todo alivio, constituirse en su única protección, ella que reúne en sí la más absoluta fidelidad y el coraje intrépido de muchas legiones devotas:

"... incipe Magnum
sola sequi . . . . "

$$
\text { VV, 80-81. }
$$

Y por cierto que Cornelia es bien digna de su fe: ni usa una sola palabra de imprecación contra los dioses a causa del turbio porvenir que se les avecina; solamente se lamenta que un patrimonio de grave desdicha recaiga sobre ella y la convierta en ser funesto para quien la ha elegido cual compañera de la vida. Se siente responsable de los azares en Siria y de la trágica derrota de Craso y se lamenta haber quedado viuda de su primer marido para ser fatalmente conducida por los Manes a Pompeyo y señalar la caída en los campos de la Tesalia.

Cornelia a fin de apartar de su amado consorte la implacable adversidad del Destino llega hasta el extremo heroico de una mujer que ama: rendir justicia a la rival. Ofreciéndose a ella como víctima propiciatoria de perdón a Pompeyo, tiene palabras que solamente quien vive y palpita por un único y santo afecto, puede expresar:

"ubicumque iaces, civilibus armis nos hos ulta toros ades huc atque exige poenas, Iulia crudelis, placataque paelice caesa, Magno parce tuo .........."

$$
\text { VV, 102-5. }
$$

Cornelia sigue a su marido durante la fuga; mas ¿adónde dirigirán las velas estos miserables? ¿Qué lugar podrá ofrecer segura hospitalidad al enemigo de Julio César?

Pompeyo escoge Egipto, confiado en un antiguo ligamen de amistad que habría favorecido el sagrado vínculo de la hospitalidad.

Habiendo llegado a las playas egipcias, Cornelia, présaga, desea seguir a su marido en la barca tolomaica en donde ya asecha la traición; pero Pompeyo ordena a Cornelia y a su hijo permanecer en la nave: 
6

$\ldots \ldots$ in hac cervice tyranni

explorare fidem .............

Y cornelia sigue con ansia todos los vaivenes de la nave y los ademanes y comportamientos de quienes circundan a su marido.

Lucano describe admirablemente el tormento de Cornelia al ver a Pompeyo traicionado por mano de viles sicarios, entre quienes sobresale un romano renegado, Septimio, quien desprende la cabeza del cadáver - horrible trofeo-para llevarlo al rey traidor. Ella sufre en la impotencia de recoger el cuerpo sangrante de su marido y grita y aúlla como fiera herida, sobre el alto mar y maldice su destino y atribuye a sí misma la culpa de haberlo conducido a la infame matanza y desesperada, invoca la muerte para que la conduzca al lado de su cónyugue. En él vive lo mejor de ella, igual es la esencia de su alma, idénticos fueron siempre sus intenciones y deseos: ¿por qué, pues, vivir más sin él?

“........ haud ego culpa

libera bellorum quae matrum sola per undas et castra comes nullis absterrita fatis victum quod reges etiam timuere, recepi”.

$$
\text { VIII, 647-50. }
$$

Cornelia al no poder detener la fuga de la nave, mientras se aleja mantiene fija la mirada hacia la orilla funesta y cuando ve la llama de la pira de Pompeyo, prorrumpe en fuertes lamentaciones, angustiada por verse privada de rendir el postrer tributo de devoción y afecto a los restos de Pompeyo. Y de nuevo impreca al triste Destino que le impide llorar sobre un sepulcro que encierre los restos mortales de su marido.

Ella sigue amando a Pompeyo descuartizado y abandonado sobre las arenas de aquella playa inhóspita con un ardor más vivo de aquel con que lo amó cuando Pompeyo estaba en su gloria y plenitud de poder: lo único que ahora espera es el advenimiento de un fin próximo no por obra de veneno, lazo o arma cualquiera, sino por el arrebato mismo del dolor.

Y sin embargo en aquel desesperado abandono encuentra todavía fieras palabras de romana y
Escipiónica para recomendar a Sexto los últimos deseos de Pompeyo que exigen odio eterno al enemigo vencedor y reclaman venganza por su triste final. Después recae en su mudo dolor, para el que no hay posible consuelo.

Llegadas las naves fugitivas a las playas africanas donde se reúnen otras fuerzas pompeyanas al mando de Catón y de Gneo, hijo primogénito, éste se entera por medio de Sexto respecto a la traición del huésped, el asesinato feroz y el estrago del cuerpo venerable de su padre. Anhela con furor la justa venganza y querría que de inmediato todos cuantos permanecen fieles a la noble memoria de su padre, todos se embarquen y se dirijan contra Egipto y devasten a sangre y fuego aquella tierra de maldad y con la sangre del joven, cobarde y torpe rey aplacar la gran Sombra sin paz.

Pero las sabias palabras de Catón llegan a imponerse y consiguen la calma y la moderación.

Solamente Cornelia, entre el inmenso duelo de los presentes

\section{in voltus effusa comas}

desciende a la playa llevando las insignias, las armas y las vestiduras de Pompeyo, preciosas reliquias de su gloria militar y de su alto poder en tiempo de paz; hace de todo aquello una balumba y aplica fuego a aquellos paramentos para ella sagrados. Posteriormente, recoge las cenizas y se las lleva consigo como postrer recuerdo, mientras la playa toda arde con fuegos

exemplum pietas, et toto littore busta
surgunt Thessalicis reddentia maribus ignem.

IX, 179-81.

Son los veteranos de Pompeyo que encienden fuegos en honor de su gran "DUX": de éstos fuegos permanecerá intacto el ardor en el corazón de Cornelia, así como el alto encomio de Catón, austeramente solemne en aquella hora calamitosa, consagra al recuerdo glorioso de los pueblos futuros las virtudes magníficas del Enemigo de Julio César. 


\section{NOTAS}

(1) Es éste un principio que la Stoa tienen en común con la Academia: en efecto lo hallamos expuesto por Sócrates en el libro V de la República de Platón.
(2) Lib. II, V. 326-380.

(3) Trat. IV, cap. 28.

\section{BIBLIOGRAFIA}

J. D. Duff. The Civil War. London, W. Heinemann, 1928.

Lucano. La guerra civile: La Pharsale. Paris, Société d'Edition Les Belles Lettres, 1926.

Marchesi, Concetto. Storia della Letteratura Latina. Milano, Casa Editrice Giuseppe Principato, 1975.
Ronconi, Alessandro. La Letteratura Romana. Firenze, Felice Le Monnier, 1968.

Ronconi, Alessandro. Storia e Antologia della Letteratura Latina, volume III. Firenze, Felice Le Monnier, 1972. 